\title{
Ação, instante e aspectualidade da representação visual: narrativa e discurso visual no fotojornalismo*
}

\section{RESUMO}

Este texto pretende averiguar, no contexto de um exame concreto de materiais do fotojornalismo, as relações entre o método estrutural de análise da narrativa e certas abordagens estéticas da interpretação das representações visuais: concentramo-nos no problema da significação do instante, como ponto cardinal da resolução do modo como as imagens fotográficas reportam-se às ações; o problema da instantaneidade na fotografia exprime, ao mesmo tempo, um aspecto visual de arresto da integridade temporal das ações e também uma função própria ao discurso narrativo. Interessa-nos avaliar as correlações entre os regimes da representação e as estruturas da percepção como problema atinente ao modo como Umberto Eco propôs as relações entre iconografia e códigos perceptivos; a noção de aspectualidade, oriunda de teorias estéticas contemporâneas, nos parece central para explorar estas relações entre a imagem e a percepção

\section{PALAVRAS-CHAVE}

fotojornalismo

narrativa

ação

\begin{abstract}
This text intends to seek the relation between Structuralism in textual analysis and some approaches of contemporary aesthetic theories on the issue of the interpretation of visual representations: we focus on the problem of the meaning of the instant, as a cardinal point of the ways by which photographic images report themselves to actions; in these terms, we take the problem of the photographic instant as simultaneously expressing the arrest of action's temporal integrity and as a proper narrative function. We are especially interested in the evaluation of the connections between representational regimes and perceptual structures, in the very same way Umberto Eco approaches the remissions between iconography and perceptual codes; the notion of "aspectuality", introduced here by contemporary aesthetic theories, seems to be a central item in order to enable the exploration of the relation between images and perception.
\end{abstract}

\section{KEY WORDS}

photojournalism

narrative

action

\section{Benjamim Picado \\ Professor do Programa de Pós-Graduação em Comunicação e Cultura Contemporâneas da UFBA/BA/BR \\ jbpicado@hotmail.com}

Pretendemos estabelecer aqui um campo de provas da análise de certos modelos de uma discursividade associada às representações visuais e que consideramos própria ao universo do fotojornalismo contemporâneo. Do ponto de vista dos marcos teóricos dessa análise, já examinamos em outras oportunidades alguns vínculos que ligariam hipoteticamente o modelo estrutural da análise da narrativa, proposto por Roland Barthes (Barthes, 1966), a certos problemas de uma abordagem estética do discurso visual.

Tal abordagem, de algum modo, estaria urdida na origem de um programa de pesquisa semiológica das mensagens visuais, em Umberto Eco (Eco, 1968), e que prometem uma combinação entre problemas afeitos às disciplinas do signo e da interpretação com uma longa tradição de questões das teorias estéticas e das ciências da arte. Examinando anteriormente o modelo estrutural de análise da narrativa de Barthes, supúnhamos encontrar ali os elementos que nos permitiriam superar esse fosso metodológico que se estabeleceu historicamente entre esses dois grandes programas da análise estrutural - a abordagem semiológica e a pesquisa sobre as funções próprias do discurso narrativo.

Em nosso entendimento, esse suposto aparte estabelecido entre os regimes sígnico e textual não se justificaria, em face do modo como Barthes sugeriu (quase simultaneamente ao avanço de um programa de pesquisas semiológicas), uma abordagem das formas narrativas. Desta forma, esse último capítulo do método estrutural em ciências humanas poderia ser retomado para iluminar, em retrospecto, as eventuais aporias em que sua concepção de semiologia acabou por se instalar. Em especial, uma maior atenção ao problema da análise das narrações permitiria recolocar, ainda em sede semiológica, a questão do regime textual supostamente inerente às formas visuais (Picado, 2006).

\section{Semiose visual, sentido narrativo e as antinomias da semiologia da imagem}

No que respeita o argumento que desejamos construir, propomos nos deter na caracterização que Barthes fez do nível mais elementar das estruturas narrativas. Das funções: neste contexto, a maior parte das energias dedicadas por Barthes na definição das estruturas do discurso narrativo teve precisamente por objeto a caracterização deste nível puramente estrutural do discurso narrativo.

Além disso, é no plano das funções que se estabeleceu para Barthes o problema central da fixação de uma espécie de nível sintático do sentido narrativo, em sua manifestação mais caracteristicamente estrutural (e não no 
das ações ou das narrações, que lhe são hierarquicamente superiores). É neste último aspecto que nos parecem emergir as sugestões mais luminosas de uma abordagem possivelmente estrutural das regências comunicacionais da imagem fotojornalística, para além da estrita subordinação dos fatos semiológicos aos princípios normativos da langue.

Assim sendo, a decomposição desse primeiro nível hierárquico das narrativas identifica nas funções um patamar de relações entre os termos do discurso narrativo que se define por uma pura linearidade (ou consequencialidade) dos elementos relacionados: nesse mesmo nível, se instaura uma espécie de sintaxe funcional das narrativas, uma relação puramente oposicional (nos dizeres de Barthes, distributiva) entre os elementos de uma ação (como a compra de uma arma, de um lado, e a iminência de seu uso em algum ponto das ações).

Sem que nos dediquemos necessariamente à integração de todos esses aspectos das funções narrativas na ordem das ações e da própria narração (que são o prolongamento da introdução que Barthes propõe à análise estrutural da narrativa), examinemos estas questões à luz daquilo que o próprio Barthes propôs sobre a significação da imagem, quando a examina a partir dos problemas da retórica da publicidade ou do discurso informativo da imprensa.

Na primeira fase de sua aventura semiológica (Barthes, 1961 e 1964) nos interessa examinar o modo como a semiologia barthesiana pareceu haver desconsiderado a possibilidade de assimilar as regências discursivas da imagem, a partir de uma perspectiva mais francamente estrutural (no mesmo modo como ele pôde realizá-la para o estudo das narrativas).

Pois é justamente no nível destas funções narrativas que a questão da regência textual da imagem poderia ter sido pensada na sua dimensão da articulação ou de valor estrutural mais próprio (portanto, independente do atravessamento por um princípio de linguisticidade): neste caso, poderíamos pensar em como as funções estabelecem níveis de relações entre os elementos constituintes de uma forma visual (gestos e expressão fisionômica dos personagens, enquadramentos, cores, tonalidades, distribuição de elementos no espaço, composição, entre outras).

Deste modo, ficaríamos em melhores condições para dimensionar os elementos propriamente icônicos da imagem como operadores do discurso visual da fotografia: estaríamos, portanto, livres de ter que assumir (como fez Barthes em boa parte de sua obra estritamente semiológica) que a iconicidade das representações visuais seria estruturalmente infensa a alguma definição em termos de um código propriamente analógico ou de algum outro tipo de princípio constringente para seu funcionamento.

Neste sentido é que avaliamos, por exemplo, o modo como o problema da significação do instante na fotografia assume a dimensão pela qual as teorias semiológicas poderiam tê-lo tomado propriamente em causa. Não conseguimos enxergar como foi teoricamente possível que essa rendição instantânea das ações (tão própria à significação fotográfica) pudesse haver sido alienada de sua dimensão de particular functional de uma estrutura narrativa, e que se realiza precisamente através deste arresto sobre a imagem (ou melhor ainda, deste modo como a imagem significa por roubar do acontecimento aquilo que mais lhe seria próprio).

Nestes termos, ao assumirmos certas indicações de uma abordagem estrutural das narrativas (no sotaque que Barthes lhe conferiu), não há como evitarmos que o tratamento do instante fotográfico seja restituído na sua condição de função narrativa, no sentido mesmo que a análise estrutural, por ele mesmo proposta, atribuiu a esse conceito. De tudo isto, o mais interessante é que este concernimento com os níveis articulatórios mais básicos em que a matéria visual das imagens é regenciada para fins comunicacionais (e que implicaria uma hipotética assimilação da análise das funções na abordagem semiológica das mensagens visuais) se insinua igualmente em outras oportunidades da origem dos saberes semióticos, no mesmo período em que Barthes ensaia a constituição disciplinar da semiologia.

Identificamos assim, essa mesma preocupação com os níveis sintagmáticos da comunicação pelos ícones visuais, por exemplo, no modo como Umberto Eco argumenta, em La Struttura Assente, sobre os desafios metodológicos implicados na definição das regências estruturais de sentido próprias ao recurso comunicacional da fotografia, em contextos retóricos e narratvos (Eco, 1968). A combinação dessas mesmas referências teóricas e metodológicas da análise nos vai permitir um acesso fenomenologicamente mais rentável ao valor discursivo dos materiais visuais do fotojornalismo.

Nesta direção, desejamos segmentar neste exame concreto dos materiais visuais suas características propriamente icônicas de significação, sem perdermos de vista a necessidade de que também firmemos nestas imagens as funções pelas quais nelas o exame de suas características internas permita-nos estabelecer as marcas dos regimes textuais que caracterizam sua função propriamente comunicacional, nos contextos mediáticos apropriados.

\section{A dimensão mito-funcional do instante fotográfico}

Até este momento, em nossa pesquisa, nos fixamos especialmente na questão da representação dos temas de ação no fotojornalismo, nos dois níveis em que este problema se apresenta para uma abordagem que combina, ao mesmo tempo, regimes textuais e plásticos da imagem. Assim, a análise tenta coordenar, em um mesmo espaço, a questão dos modos nos quais a narrativa representa a ação em sua dimensão de evento que se desdobra em seu aspecto temporal (portanto, que se exprime numa durée determinada) e, por outro lado, o fato de que a imagem fotográfica se reporta a essa dimensão 
temporal através de sua rendição em um único instante.

Questão esta que, ainda uma vez mais, nos obriga a assimilar os problemas de uma teoria da narrativa (normalmente restrita às suas manifestações no contexto das formas literárias) às interrogações sobre a questão da fixação do tempo em certos tipos de imagens que aludem a um saber claramente pressuposto em narrativas (como nas pinturas de temas históricos ou míticos).

No caso especial do discurso visual do fotojornalismo, esta combinação entre uma estrutura narrativa e os aspectos de modelação icônica que constituem a representação visual (a partir de seus aspectos plásticos), justifica que coloquemos esses materiais na condição de campo de provas de uma análise mais específica dos regimes textuais na imagem.

Passemos, assim, ao exame concreto de certos destes clichés, sabendo de antemão que nelas encontramos muito fortemente um apelo ao que podemos chamar de temas da ação (simplesmente são motivos que exprimem, na retenção de um instante especial, a noção de desdobramento e de integração temporais que são próprias a uma representação narrativa de um acontecimento). Vejamos um primeiro destes casos mais característicos do problema em discussão aqui (fig. 1):

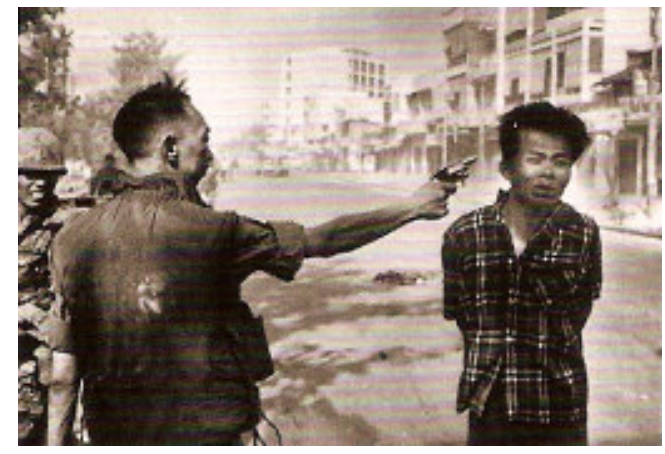

Figura 1: Eddie Adams, "Execution of a Vietcong Prisioner" (1968) - Associated Press

Neste exemplar clássico da história do fotojornalismo podemos afirmar, sem grandes temores, que o caráter patentemente dramático da imagem se desprende facilmente das funções puramente reportativas, sob as quais a fotografia de imprensa está geralmente submetida (temos que separar nela, do ponto de vista dos regimes textuais sob os quais a abordamos, o que nela se narra em relação ao que encontramos nela descrito).

Com isto, queremos dizer que a análise sobre a capacidade da imagem de nos comunicar uma história (ou de gerar um sentido textual mais lato) é relativamente independente de sua relação mais decorativa com o universo do fait divers jornalístico: assim, devemos considerar o valor desta imagem para além de sua condição de mero acompanhamento visual da reportagem escrita destes fatos, tomando-a no aspecto icônico de sua representação.
Então, nada nos autoriza a supor que o efeito de discurso que lhe é próprio seja exclusivamente derivado da função de ancrage que uma legenda ou qualquer outro tipo de escritura associada à imagem pudesse proporcionar para que sua compreensão se desse de maneira mais franca, como nos ensinaram alguns dos arcanos de uma abordagem semiológica das mensagens visuais (Barthes, 1964).

Esta suposta independência do regime visual do discurso na fotografia em relação a seus aspectos reportativos traz em causa dois níveis nos quais o problema do fotojornalismo se põe para nossa interrogação. No primeiro deles, entra em jogo toda uma dinâmica de autonomização da atividade do repórter visual, característica da história do jornalismo no decorrer do último século; este processo envolve o conjunto de estratégias que o campo profissional desenvolveu periodicamente para dimensionar a função própria da presença do olhar fotográfico no centro dos acontecimentos narrados.

De todo modo, este especial conjunto de implicações ligadas ao contexto no qual o fotojornalismo se legitimou profissionalmente (especialmente no intervalo entre as duas grandes guerras mundiais), ainda que de vital importância para uma análise mais ampla das funções e da importância da reportagem visual, não se coloca no escopo momentâneo de nossas explorações.

O segundo nível da pertinência de uma hipótese sobre a autonomia na qual o fotojornalismo instaura o sentido que lhe é próprio é precisamente aquele que coloca em jogo a pertinência dos operadores de uma análise estrutural e a valorização de seu sentido de composição, observado em um corpus concreto de imagens. Portanto, numa perspectiva mais afastada, diríamos que esta mesma autonomia se exprime através de uma ênfase sobre os níveis afetivos e sensacionais pelos quais certas imagens clássicas do fotojornalismo funcionam como amostras da excelência da reportagem visual.

Assim sendo, se recensearmos um bom número destas imagens, notaremos uma clara predominância do impacto emocional e sensorial que as acompanha no lugar de, por exemplo, qualquer indicação mais clara de uma coligação com a singularidade histórica, política ou social dos mesmos acontecimentos. Pensando na hipótese de certos pesquisadores que trabalham com a noção de um modelo poético de análise de materiais expressivos, deveríamos levar em conta a natureza dos programas de produção de efeito que encontramos geralmente associados ao universo do fotojornalismo (ou, ao menos, de seus exemplares mais clássicos).

Nestas imagens, diríamos que os aspectos cognitivo ou informacional são bem menos predominantes nestas imagens do que aqueles que caracterizam a programação de efeitos mais próximos da afecção emocional ou de uma sensibilidade estética (Gomes, 2004). Entretanto, se nos acercamos um pouco mais destes clichés fotográficos, notaremos que uma tarefa importante se descortina para a análise dos regimes de discurso associados aos 
exemplares do fotojornalismo que examinamos.

Se supomos esta deflação sofrida pelo caráter informacional ou historicamente singularizador da imagem, é legítimo que nos perguntemos sobre as razões desse mesmo fenômeno, mas sobretudo sobre como é que se dá nas imagens a valorização das outras dimensões de seu funcionamento discursivo (isto é, como elas são capazes de mobilizar nosso pathos e nossa sensibilidade).

A resposta à primeira questão, insistimos, requer uma outra sede de argumentação, que faz apelo à história dos processos de legitimação do fotojornalismo e das estratégias adotadas no campo profissional para este fim - e que já dissemos que está momentaneamente fora de nosso alcance. A segunda questão é precisamente a que nos interessa mais de perto: ela tem por pressuposto o modo como a reportagem visual se consolidou enquanto protocolo da informação jornalística.

Nesse aspecto, reconhecemos a predominância de um apelo afetivo e sensorial, no modo pelo qual estas imagens regenciam a produção de seus sentidos, especialmente na relação dos leitores com o acontecimento. Assim sendo, o que o tratamento desta segunda questão nos reclama é uma maior atenção às modalidades internas de configuração do sentido na imagem fotojornalística, a partir de todos aqueles elementos nos quais a imagem visual invoca a relação com o espectador, sob o signo do testemunho sensorial e vicário do acontecimento.

Enfim, para o efeito do exame da imagem de Adams, cumpre que desconsideremos momentaneamente que se trata da ilustração fotográfica de uma matéria jornalística sobre a execução de um soldado do Vietnã do Norte, pelas mãos do Chefe de Brigada Nguyen Ngoc Loan, do exército sul-vietnamita, ocorrido numa rua de Saigon, no primeiro dia do mês de fevereiro de 1968. Sobretudo, temos que considerar nesta foto o que faz com que ela perdure em seu poder de evocação de uma situação narrativa, para muito além desta sua relação com um evento particular de uma guerra havida há quase 40 anos.

Enfim, temos que nos perguntar sobre os modos como esta imagem clássica do fotojornalismo do último século punge questões sobre a potência narrativa das imagens. Entram em jogo aqui questões sobre o modo como a fotografia é capaz de infundir historicidade a acontecimentos de toda sorte: em nosso modo de entender as questões sobre os fundamentos da textualidade própria do fotojornalismo, seu sentido se revela muito mais na relação da imagem fixa com o tempo interno das ações do que propriamente na sua coligação factual (ou em jargão semiótico, sua indexicalidade).

O que caracteriza mais fortemente o poder evocador desta fotografia é, portanto, o fato de que ela exprime, no nível de um instante único, um sentido de desdobramento que é próprio às ações das quais esse segmento foi arrestado: a fotografia representa uma ação completa, mas como que condensada na forma da pura iminência de sua consumação última; ela manifesta-se como urgência de um desdobramento que a imagem mesma (na sua condição de mero átomo) não é capaz de exprimir, na sua integridade. No sentido consequencial que carateriza o fluxo das narrativas, esta imagem representa um momento imediatamente anterior ao ponto de resolução da ação.

Do ponto de vista daquilo que define, por exemplo, na análise estrutural da narrativa, a pura linearidade na qual as ações sintetizam as relações entre seus elementos constituintes (por exemplo, tomar em mãos uma faca e empregá-la em seguida na consumação de um crime). Esta foto representa aquilo que Barthes designa no seu modelo de análise como sendo um núcleo, ou seja, um aspecto destacado (uma subclasse) das funções narrativas.

Em geral, do ponto de vista de seu exame mais detido, a finalidade desses núcleos é a de permitir que se isolem, no contexto integrado de ações mais completas, um certo conjunto de elementos que funcionem como segmentos sintaticamente separados daqueles outros dados que, assimilados aos primeiros, operarão um sentido propriamente discursivo no nível funcionalmente superior das ações propriamente ditas.

No caso da fotografia, este aspecto da retenção de uma ação mais íntegra em um de seus instantes isolados tem especial correlação com este dado específico da análise estrutural do discurso narrativo: segundo Barthes, os núcleos têm uma função propriamente cardinal, pois visam introduzir um segmento das ações que servirá como uma espécie de indicador de seu desdobramento possível ou mesmo incerto; na fotografia de Adams, essa função é expressa no modo como a organização dos elementos retidos pela fotografia (nos deteremos aqui em especial na integração entre o gesto do agressor e a fisionomia da vítima) opera como um dado sugestivo desta iminência.

Ao estabelecermos essa função cardinal do instante fotográfico, não estamos desconhecendo que sua correlação com o desdobramento das ações é relativamente livre com respeito ao que esse arresto sugere. Há uma interessante proporcionalidade entre o valor dramático deste instante e a considerável incerteza sobre a consumação do ato pelo qual o oficial executará seu inimigo; a fixidez do momento rendido na imagem reforça este aspecto de potencial indeterminabilidade deste segmento da ação, fazendo com que este desdobramento se suspenda na sua efetivação, mas se mantenha permanente num horizonte de possibilidades considerável, o que gera um efeito de perpétuo gerúndio, característico das representações de ações tomadas a partir da rendição de um instante.

Nestes termos, o exame dos modos como a fotografia segmenta, no plano de um instante, um núcleo cardinal de ações que se integram num patamar funcionalmente superior (o das ações mais íntegras), nos permitiria tratar dos temas de ação no fotojornalismo como manifestações de uma autêntica forma narrativa, constituída atra- 
vés de materiais icônico-visuais, aqui vertidas numa perspectiva estrutural, similar àquela que nos é sugerida por Barthes. Então, a assimilação de certos aspectos desta modalidade da análise das formas textuais nos permitiria inclusive escapar a certas das aporias que o próprio Barthes infirmou para as abordagens semiológicas da imagem e que acabaram por condenar o problema da gênese do sentido nas representações visuais a uma relação de subordinação com respeito aos regimes propriamente linguísticos da produção discursiva.

\section{Configuração visual e função cardinal do instante fotográfico}

Teríamos que considerar, entretanto, os modos mais específicos nos quais a fotografia é capaz de se restituir a esta ordem das narrativas e que não são necessariamente assimiláveis às formas literárias às quais o problema foi, em geral, assimilado. Neste caso, somos forçados a levar em conta um conjunto de elementos próprios a outros tipos de abordagem da análise da imagem, e através dos quais esse sentido de desdobramento se manifesta, por exemplo, na função que se atribui à representação de um instante.

Nestes termos, precisamos nos interrogar sobre o caráter mesmo deste instante, ou seja: o que a imagem de Adams tem de tão exemplar em seu modo particular de figurar uma ação que se desenrola perpetuamente? Digamos isto de outro modo: o que faz desta imagem um instante, não apenas em seu aspecto filogenético (não apenas pelo fato de ser o resultado de um processo mecânico de retenção ótica), mas na sua ontogênese mesma, isto é, em seu aspecto de significação visual de um acontecimento?

Nos interessa, assim, destacar a economia simultaneamente semiósica e textual na qual os elementos que definem esta imagem operam sua funcionalidade, a partir da atenção que nela dediquemos a elementos tais como o caráter de sua composição visual (cuja origem é muito difícil discutir nos limites deste texto, mas que prometemos elaborar em outras oportunidades). Esses elementos unificam numa forma visual alguns de seus dados (o enquadramento dos motivos, a iluminação do ambiente, o jogo dos contrastes e, especialmente, o tratamento dos gestos e da atitude das personagens).

É precisamente no jogo configurativo de tais elementos que vamos encontrar uma suposta chave para a análise do tipo específico de regência textual pelo qual coligamos a representação das ações, a partir de sua rendição em um instante (Picado, 2008). No caso da fotografia em questão, há que se ter em conta que a maneira pela qual esta imagem segmenta num instante o sentido mais íntegro da ação à qual se reporta é algo que se manifesta em um aspecto desta mesma imagem (com isso queremos dizer que o que faz com que ela funcione como índice de desdobramentos próprios a um acontecimento é algo que está contido no interior mesmo da imagem).
Numa perspectiva semiótica, o significado desta afirmação é o de nos chamar a atenção para o fato de que a regência narrativa sob a qual analisamos o arresto do tempo das ações na forma de instante decorre, por sua vez, do modo como este aspecto que é próprio à imagem constitui-se sob a espécie de um ícone visual. Na base desta mesma plataforma, eliminamos qualquer esperança de que a significação fotográfica no fotojornalismo (ao menos naquilo que a imagem de Adams parece exemplificar) possa ser derivada do suposto compromisso ontológico que caracteriza a metafísica do processo fotográfico (a coligação existencial entre o dispositivo técnico de fixação e a significação dos motivos visuais).

Assim sendo, uma teoria da narrativa na imagem fotográfica só pode se instaurar, reconhecendo liminarmente as funções integradoras da materialidade de que se constitui a imagem, assim que se conceda que esta matéria icônica (assumida na condição de modelação plástica da imagem e oriunda dos regimes nos quais a mesma é percebida e sentida) antecede a regência textual sob a qual a encontramos funcionando, no contexto do fotojornalismo.

Do que estamos falando precisamente aqui? Se tomarmos a fotografia de Adams em questão, notaremos que a capacidade da imagem reter sob o instante o sentido de iminência do prolongamento ou da consumação de uma ação não é exclusivamente resultante do modo como funções narrativas se inscrevem na imagem, mas precisamente do modo como certos de seus aspectos visuais estão destacados para nossa visão.

Ou seja, é um problema relativo ao modo como a fotografia é capaz de nos restituir a uma espécie de experiência de testemunho ocular e do modo como esta experiência é construída no plano dos elementos que constituem a imagem, por assim dizer, desde seu interior (é o que queremos dizer com a ideia de que esses aspectos da imagem são partes do que a caracteriza enquanto ícone visual, enquanto modelação de seus elementos constituintes para um tipo muito específico de visão, a visão do testemunho).

Entre tantas outras coisas, há em primeiro lugar, uma integração que se constitui na relação vetorial pela qual esta imagem correlaciona o gesto ameaçador do oficial e a expressão fisionômica da vítima, em sua agonia. É precisamente esse jogo linear da composição que se constitui como um aspecto através do qual somos reportados à consumação iminente da execução de um rebelde; esta integração propiciada na composição não é acidental (não se constitui, portanto, como característica exclusiva desta fotografia em particular), e sim réplica de um cânone visual, de um dado estrutural de todas as imagens que exprimem este sentido de ação, através de sua assimilação ao instante.

A função própria ao tratamento da expressão corporal e dos gestos no fotojornalismo caracteriza o modo como estas imagens funcionam a título de representações de uma ação: em outros contextos de nosso exame, 
identificamos uma significativa relação de redundância que se estabelece entre a fixação instantânea do gesto das personagens e sua relação com as ações nas quais as mesmas se encontram empenhadas. Em certos momentos, essa repercussão tem fundamento na simbolicidade convencional do gesto, mas também encontra correlação com os aspectos somáticos e expressionais da comunicação corporal ou gestual (Picado, 2005).

Para avaliarmos o devido alcance que a apreciação desses aspectos icônicos da imagem assumem na correlação com as regências textuais do material icônico, basta que contemplemos um outro desses clássicos do fotojornalismo, de resto bastante dissimilar à imagem de Adams, sobretudo em seu tema (fig. 2):

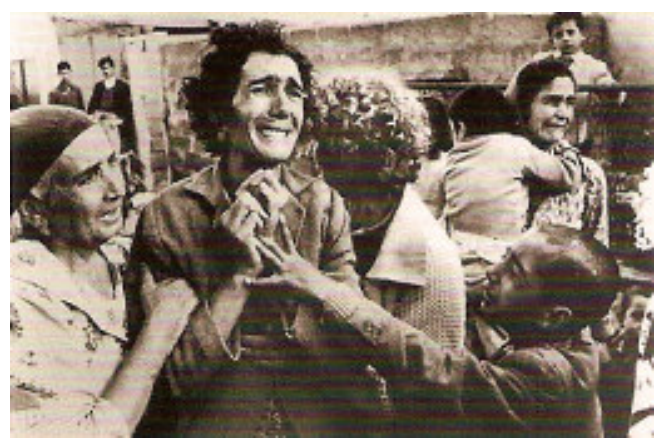

Figura 2: Donald McCullin, "Turkish Women" (1964) - The Observer, Quick, Life

O tema da ação neste outro clássico do fotojornalismo não se exprime, como no primeiro caso, pela ligação com a função cardinal do instante (tomado na condição de imediata antecedência àquilo que se desfiará, na ordem consequencial das ações): diferentemente do caso da fotografia de Adams, o modo como esta imagem se converte em sintagma narrativo está muito mais associado àqueles aspectos em que a ação é expressa a partir daquilo que ela deixa de sedimentos, logo após a consumação de sua força motriz.

Em termos mais precisos, não podemos desconhecer que as ações estão decerto preservadas ao olhar analítico nesta fotografia: não é senão o título da imagem que nos informa se tratar de mulheres turcas que vão reconhecer os corpos de seus parentes recém-chegados, vítimas de um conflito militar com os gregos, na ilha de Chipre. Entretanto, há uma diferença de perspectiva no modo como o conflito é visualizado por McCullin, pois o sofrimento das mulheres fotografadas significa o acontecido na perspectiva das paixões que resultaram de uma ação prévia.

Ainda assim, do mesmo modo que na primeira imagem, a construção de um sentido propriamente consequencial para este instante dependerá da capacidade da imagem de deixar segmentar, em seu próprio interior, estes elementos de sua composição. Ainda uma vez mais, chamemos estes dados da imagem de seus aspectos, mas agora restituamos a fonte de nossos discursos ao significado filosófico desta noção (e à importância que este conceito tem para a análise das regências textuais do fotojornalismo que pretendemos pôr em marcha).

Certos autores falam da aspectualidade como sendo um domínio das representações visuais pelo qual se pode considerar aquilo que um sistema simbólico de base de uma dada imagem chega a destacar ou não como sendo pertinente à visualização de seus motivos (Lopes, 1996).

A ideia da aspectualidade das representações visuais é uma decorrência da tese sobre a intrínseca seletividade na qual uma imagem é capaz de fixar seus motivos ou temas: se supomos, por exemplo, que a significação de uma representação visual é, de algum modo, restituível às estruturas da percepção (é o caso de Gombrich), então temos que estabelecer que esta relação entre representar e dar-se a perceber já implica em seleção de aspectos, fundada nos princípios de um sistema da representação historicamente determinado.

Em suma, é a seletividade de aspectos visuais que caracteriza os conteúdos da imagem: aquilo que ela é capaz de segmentar como elemento de sua visualização é aquilo que conta para o modo como apreciamos ou analisamos os regimes de sua significação. No caso da fotografia de Adams, é evidente que a profundidade do campo no qual a imagem da execução se apresenta é um aspecto muito menos saliente de sua significação do que aquele da forte vetorialização horizontal com a qual se apresenta a execução em seu momentum: a função que a expressividade do gesto do executor (e seu prolongamento linear até nos fazer encontrar a fisionomia agônica da vítima) integra nessa imagem o tempo da consumação, materializado na forma de uma pura iminência.

No caso de McCullin, por outro lado, ainda que o motivo da imagem não aluda a uma ação nesse seu aspecto de um desfecho iminente (pois, se a foto se liga a uma ação, esta já se consumou, propriamente), a qualidade mais importante rendida nesta imagem é precisamente a mesma pela qual um motivo de ação clássico se manifesta, isto é: através da integração entre os gestos das personagens e a expressão de padecimento que se imprime em cada um de seus rostos (ou especialmente, em um deles).

De todo modo, esse sentido de unificação dos elementos não respeita o mesmo tipo de organização vetorial próprio à fotografia de Adams: predomina em McCullin uma estrutura de remissões entre gestos e fisionomia que privilegia algo como um percurso elíptico (ou ainda, centrípeta) que nosso olhar estabelece sobre esses mesmos aspectos dramáticos da expressão gestual e fisionômica na fotografia.

Mais uma vez, o fato de que somos reportados a uma ação, na forma de uma estrutura narrativa (e que confere aos elementos aspectuais da imagem o estatuto de núcleos ou de índices funcionais de uma ação) é apenas a 
resultante de um outro processo (segundo Umberto Eco, mais propriamente analítico do que o narrativo), e pelo qual os elementos da imagem são operadores da geração de um sentido de participação sensorial no espaço das ações.

Nesse sentido, a importância de nossa tese é a de que o regime narrativo sobre o qual a imagem fotojornalística opera implica em certo paradigma comunicacional, que não é mais o da informação daquilo que se representa, mas o de nos fazer participar de um acontecimento. Nestes termos, o discurso visual próprio ao fotojornalismo (quando o consideramos à luz desses exemplos que analisamos) arrasta consigo uma ideia de testemunho, pela qual a função da representação é a de instaurar uma espécie de vicariedade da experiência visual.

Isto significa que ao nos darmos conta do que vai pelo mundo através destas imagens, não deixamos de entrar certo regime de gozo (e que se define pelo modo como somos implicados enquanto partícipes do universo visual que se instaura fotograficamente). Em outros momentos de nossa exploração aos regimes textuais da imagem fotojornalística, destacamos esse tipo de recurso característico das narrativas visuais, e que consiste em gerar no espectador uma espécie de simpatia sensorial, à qual os historiadores definem com sendo o caráter vicário do testemunho que a imagem propicia aqueles que a apreciam.

A estrutura de base da experiência das imagens narrativas contempla precisamente esse tipo de efeito de participação do olhar no universo criado pela imagem: na fotografia de McCullin, esse aspecto do tratamento expressivo dos gestos e das fisionomias destaca precisamente esse vínculo entre a ação passada e o sofrimento presente, de tal modo que os gestos rendidos fotograficamente assumem mais a função de sintomas do que de símbolos.

Este processo se define pelo modo como um código representacional próprio à imagem, antes de ser constrito pelos princípios de uma organização narrativa das ações, é restituído aos princípios percepcionais da organização do mundo visual e, em especial (no caso de sua assimilação à forma narrativa), aos princípios pelos quais a imagem funciona como uma réplica de uma experiência testemunhal construída em determinados de seus aspectos maMECOS

\section{NOTAS}

* Para o amigo Wilson Gomes, com quem me habituei a discutir essas coisas, quase sempre em solilóquio.

\section{REFERÊNCIAS}

BARTHES, Roland. La message photographique. In: Communication, 1961.

La rhétorique de l'image. In: Communications, 1964.
. Introduction à l'analyse structural des recits. In: Communications, pp.1-27, 1966.

L'Obvie et l'Obtus. Paris: Minuit, 1992.

ECO, Umberto. La Strutura Assente. Milano: Bompiani, 1968.

FRESNAULT-DERUELLE, Pierre. L'Éloquence des Images. Paris: PUF, 1993.

Le Silence des Tableaux. Paris: L'Harmattan, 2004.

GOMBRICH, Ernest. Art and Illusion. New York: Princeton University Press, 1959.

The Image and the Eye. London: Phaidon, 1982.

GOMES, Wilson. Princípios de Poética com ênfase na poética do cinema. In: Comunicação, Representação e Práticas Sociais (Miguel Pereira, Renato Gomes e Vera Follain de Figueiredo, orgs.). Rio: Editora da PUCRio: pp. 93-125, 2004.

HOPKINS, Robert. Picture, Image and Experience. Cambridge: Cambridge University Press, 1998.

LOPES, Dominic. Understanding Pictures. Oxford: Clarendon Press, 1996.

PICADO, Benjamim. Olhar testemunhal e representação da ação na fotografia. In: e-compós, vol. 3: pp. 1-29, 2005.

Das Funções Narrativas ao Aspectual nas Representações Visuais: notas sobre modos de interpretar imagens. In: Contemporânea, 2006.

Le temps des gestes et l'arrêt sur l'image dans le photojournalisme: entre la rhétorique corporelle et le pathos iconique. In: Image $\mathcal{E}$ Narrative. n. ${ }^{\circ} 23$. Disponível em www.imageandnarrative.be/Timeandphotography/picado.html.

RICOEUR, Paul. Narrative time. In: Critical Inquiry, pp. 169-190, 1980.

SAVEDOFF, Barbara. Tranforming Images: how the photography complicates the picture. Ithaca: Cornell University Press, 2000.

SCHNEIDER, Greice; PICADO, Benjamim. Construção de Mundos em Fotografias de Representações: supressão e ambiguidade em Robert Doisneau. In: Significação. 22/1: pp. 59- 78, 2004. 